\title{
Gemini telescope project shifts into high gear
}

Washington. With a lot to do and not much time, an international collaboration to build two 8-metre telescopes by the end of the decade has put Sidney Wolff temporarily in charge of the \$176-million project.

Wolff has taken a six months' leave from her position as director of the National Optical Astronomy Observatories (NOAO), which operates three major facilities with funding from the US National Science Foundation. The telescopes, known as the Gemini Project because of twin sites in Hawaii and Chile, were originally intended to be funded entirely by the United States. But in the past three years the project has become international, with the United States putting up half the total, Britain paying 25 per cent and Canada 15 per cent. The remaining 10 per cent is being sought from one or more countries in Latin America, including the host country of Chile.

Wolff was enlisted as a troubleshooter precisely because of the additional work required to pull off such an arrangement. "Being an international collaboration makes it much more complicated", says Bob Bless, an astronomer at the University of Wisconsin and a member of the project's eightmember international advisory board. "A lot of things have to happen in the next next few months, and it seemed to be more efficient to let the technical people do their thing and get somebody else to handle the administrative aspects. Sidney is already familiar with the project, and she's also a terrific administrator."

Wolff says that she must work out the financial arrangements as soon as possible so that scientists can know how much money is available for the two telescopes. The nature of the collaboration will be spelled out in a memorandum of understanding, expected to be signed later this summer, followed in the autumn by a detailed description of each country's contribution to the project. The entire package must be ratified by the board in November, she says, to keep the project on schedule.

One technical issue that must be resolved quickly is the final design for the two telescopes, which will make infrared as well as optical observations. Three companies are competing for the type of mirror to be used in the telescopes, two US companies and one from Germany.

The telescope on Mauna Kea, Hawaii, is expected to see first light by the end of 1998 . Its nearly identical counterpart, adjacent to the Cerro Tololo Inter-American Observatory in Chile, should become operational two years later.

However, that schedule depends heavily on whether NSF can deliver its share of the funding on time. The project received only $\$ 12$ million of the $\$ 16$ million requested for the current fiscal year, which ends on 30 September, after Congress reduced NSF's overall budget request. The agency's re- quest for next year, now before Congress, will almost certainly be trimmed again.

"Last year Gemini was taxed to support other large projects in the physical sciences", says Bless. "But NSF has assured us that they consider the project to be very important, and the fact that it's an international effort gives it a high visibility."

Wolff is not quite so optimistic. "The cuts won't hurt us this year", says Wolff, "but next year the impact would be felt on the telescope's enclosure and its primary mirrors. Even if we get our request for FY [fiscal year] 93, it's not clear that we will have enough money to do the job right. We really needed $\$ 21$ million to make up for what we lost in 1992, but we only asked for $\$ 17$ million."

NSF is the executive agency for the project, which is being managed by the same coalition of research universities that runs NOAO. But Julie Lutz, director of NSF's astronomy division, says that it is harder for the United States than for other countries to sustain a long-term scientific collaboration because the entire US budget is reviewed annually by Congress.

Wolff says that she may need more than six months to accomplish everything that must be done. At the same time, she says that scientists must know by the end of the year how much they have to spend. Any delays, of course, invariably increase the cost of the project.

Jeffrey Mervis

\section{Star wars - the astronomers strike back}

London. Astronomers are becoming more aggressive in trying to protect their 'laboratories' from pollution.

At the end of this month in Paris, researchers at a conference organized by the International Astronomical Union (IAU), the United Nations Educational, Scientific and Cultural Organization (UNESCO) and the International Council of Scientific Unions (ICSU) will try to extend legislation protecting unique Earth-bound sites to locations with especially good skies or low levels of radio noise. A week earlier, astronomers attending a symposium as part of the University of Chicago's centennial anniversary will propose a multilateral treaty to protect near-Earth space from the hazards of satellite debris, a measure that would considerably benefit astronomers.

The Paris conference is ostensibly an occasion to debate the issues of pollution on an international stage. It is expected to close with a declaration on the need to reduce adverse environmental impacts on astronomy. A pre-conference draft calls for reduced levels of outdoor lighting, a sus- tained presence in the competition with the communications industry for radio wavelengths and measures to reduce and remove space debris.

One new tactic that astronomers have adopted is to seek an extension of the World Heritage Site programme, run by UNESCO and the International Union for Nature Conservation. At present, this programme is used to protect valued buildings or natural environments, but not such intangibles as light and radio characteristics.

Status as a World Heritage Site does not guarantee protection - Stonehenge in England, for instance, is protected but still suffers as a result of alterations made to improve tourist access. However, designation does provide a degree of international legal recognition and a basis from which to fight possible depredations.

Radioastronomy has been increasingly harassed by the communications industry with its demands for more and more radio frequencies on which to operate and its increasing use of satellites. In the past, observatories could be hidden from ground- based sources by building them in valleys, but there is no escape from radio signals being beamed down from on high.

Despite facing great pressure from the communications industry, the International Telecommunications Union (ITU), the body responsible for regulating access to radio frequencies, reaffirmed earlier this year its commitment to keep clear certain frequencies used by radioastronomers. The ITU has also recognized for the first time the problems caused by badly filtered communications equipment.

A particularly severe source of radio noise are the GLONASS navigational satellites launched during the 1980 s by the Soviet Union. These satellites were intended to create a global net from which pilots and mariners could triangulate their position at any time. However, it soon became clear to radioastronomers that these satellites were virtually unshielded - although transmitting in the $10-20 \mathrm{MHz}$ range, the emissions could be detected up to $100 \mathrm{MHz}$ away and that each operated at a different frequency.

Ian Mundell 